\title{
Changing Times, Changing Opinions: History Informing the Family Presence Debate
}

Significant debate currently exists within emergency medicine over whether a patient's family should be allowed to observe a critical resuscitation in the emergency department (ED) ("family presence"). Proponents of this practice would like family members to have the choice to be present during these desperate efforts that are often the final moments of patients' lives. However, many medical professionals, physicians in particular, are strongly opposed to the idea, citing a wide range of legitimate concerns: that relatives will interfere with or misunderstand medical efforts, that the events will be too upsetting for relatives to bear, and that family presence will create additional stress and anxiety for the medical team. ${ }^{1-4}$ Opponents also often express the notion that family presence is a fundamentally unsound idea, contrary to all medical reason and wisdom. In the words of one trauma surgeon, "[Family presence] should not be a point of academic discussion ... . It should simply be labeled 'ludicrous."'1

Opinions denouncing family presence, such as the one above, are frequently presented as steadfast and unarguable. Yet one does not need to look very far back in medical history to find another strongly felt, seemingly indisputable belief held by the medical establishment, a belief that was completely turned on its head within a short period of time. We are referring to the fact that less than 40 years ago, many physicians considered it highly inappropriate for fathers to attend childbirth. While childbirth and critical resuscitation are very different events with very different outcomes (most of the time), they also have some important and striking similarities. Notably, both the beginning of life (childbirth) and the end of life (a frequent result of critical resuscitation) have historically been community events, widely attended by friends and family. With the advent of modern medicine, both gradually evolved from public ceremony to private act, ${ }^{5,6}$ eventually losing their places as important community rituals. Even more important similarities are found in the passion, convictions, and justifications that have underlain the opposition to allowing family observers at both of these events.

\section{THE OPPOSITION}

In the 1960s, those physicians who opposed fathers' presence during childbirth had legitimate concerns. They were worried that fathers would get in the way of the treatment of mother and baby, or otherwise interfere with patient care. ${ }^{7-9}$ They also believed that fathers might faint, get ill, or become emotional, thus diverting the attention of the medical team away from care of the patient. ${ }^{7-11}$ Physicians expressed concerns that their performance could be compromised by having fathers looking over their shoulders, ${ }^{12}$ and that husbands might misunderstand teaching discussions, making "clinical training of house staff in labor and/or delivery rooms ... just about impossible."11 Some also thought that fathers might be emotionally unable to handle the messiness and unpleasantness of childbirth, while others worried that it was only a matter of time before the privilege of being present would be extended to other operating venues. ${ }^{7}$ Many doctors expressed concern that malpractice litigation would increase, especially if complications arose during the delivery, or if fathers saw procedures that they did not fully understand.9,11,13 The arguments expressed were often unswerving and unarguable, as in this obstetrician's statement from 1966:

... we are opposed to the admission of nonmedical people ... . Everyone ... must have a definite duty to perform and do it as well as he can. Anything or anybody who might divert attention is intolerable. This room is no place for sentimentality... .

Time and experience have taught us that concerns about allowing fathers into delivery rooms were largely unfounded. Fathers did not interfere with deliveries, and rather than feeling faint or becoming distressed, they enjoyed participating in the birth of their children. ${ }^{8-10}$ Members of the medical team found that they could work effectively with the father present. ${ }^{10,12}$ Resident training successfully continued, even when fathers were present during unplanned cesarean sections. Furthermore, doctors who had experience with the presence of fathers in the delivery room often believed that those fathers were less likely to initiate litigation. They found that fathers present during delivery were more likely to have "sympathy and understanding for the position of the doctor ..."13 and less likely to have "phantasies [sic] of mismanagement ...."

Perhaps time and experience will teach us that our current concerns about family presence during resuscitations are also unfounded. The most important point we can draw from our comparison between these two controversies is that ways of thinking often reflect 
social mores rather than absolute rights or wrongs, and that such beliefs often change over time. Thus, rather than simply dismissing family presence, we should remain open to the idea that it could be of benefit.

\section{POSSIBLE BENEFITS}

Research on family presence during resuscitation demonstrates interesting, and perhaps surprising, results. In the two largest studies done to date, at Foote Hospital in Jackson, Michigan, and at Parkland Hospital in Dallas, Texas, relatives who met certain selection criteria and who desired to participate were allowed to witness resuscitation events or invasive procedures while accompanied by a trained facilitator. Facilitators not only determined whether it was appropriate for relatives to be present, but also prepared them for what they would witness, remained with family members in the resuscitation room, and provided necessary explanations or assistance. In each of these studies, participating relatives reported that their presence was important in providing support and reassurance to the patient, as well as in relieving their own anxiety by reducing feelings of helplessness and the "agony of waiting." 14 Family members also expressed that being present with a dying loved one eased their subsequent bereavement process. The Parkland study participants indicated that their experiences helped them to understand the severity of the patient's condition and to appreciate that their relatives had received the best possible care. ${ }^{14}$

In the Foote study, $76 \%$ of family members surveyed said that they thought the experience facilitated their adjustment to the patient's death, and $64 \%$ believed that their presence was helpful to their dying family member. ${ }^{15}$ A long-term follow-up of Foote Hospital's continued family presence program found that anticipated problems failed to occur. Over the nine years reviewed, family members never interfered with a resuscitation attempt and, rather than being traumatized by watching a resuscitation, consistently made positive comments about the practice. ${ }^{16}$ Other studies of family presence have also demonstrated consistently positive responses from participating families, ${ }^{17}$ and one randomized controlled trial was ended early because ED staff became so convinced of the value of family presence to family members. ${ }^{18}$ On the provider side, a study of 114 ED personnel at a British hospital indicated that the presence of relatives at a resuscitation had no effect on self-reported stress symptoms. ${ }^{19}$

Very little work in this field has considered the patient's perspective, probably in large part due to the small number of surviving patients. However, a follow-up study at Parkland Hospital compiled the opinions of patients who had family members present while they underwent either cardiac resuscitation or invasive procedures. Although the number of patients interviewed was low $(n=9)$, the results are nonethe- less interesting. Patients thought that family presence comforted them, provided them with help, and humanized their care by reminding emergency staff of their personhood. ${ }^{20}$ Other reports of patient responses provide powerful anecdotes, such as the following from Wooster Community Hospital in Ohio, which started a family presence program in 1994: A 60-yearold man, who had successfully undergone cardiac resuscitation while his wife was in the room, later stated that he was "very much aware of his wife's presence, which was enough of an encouragement for him to continue his fight for survival."17

More recently, a survey of patients in the ED of an academic community hospital found that $77 \%$ of those surveyed would want a family member present were they to be resuscitated, although they differed on whom they would want there. ${ }^{21}$

\section{AREAS FOR THOUGHT}

Family presence policies may not be feasible at every hospital due to cost or space concerns. In the studies at both Parkland and Foote Hospitals, a trained facilitator played an integral role in the success of their family presence policies by preparing and assisting the family members and ensuring that they did not get in the way of resuscitation efforts. While some EDs may have extra personnel on hand to act in this role, many hospitals will incur extra costs by hiring and training additional staff to act in this capacity. Emergency departments interested in adopting family presence programs must also ensure that they have adequate space to allow both the facilitator and the family member in the resuscitation room.

There are a number of areas for future research on this topic. To date, the largest studies have been fairly limited, with fewer than 50 participants each. Larger studies are needed to consider the impact of demographic factors, such as race, gender, education, and prior medical history/experiences, on family preferences. Moreover, future research needs to compare observer attitudes in different clinical circumstances, such as invasive procedures vs. resuscitation, traumatic vs. medical presentations, and pediatric vs. adult cases. Additional attention should be given to the issues of resident and student teaching during resuscitation procedures and how the training and experience of the providers may impact family members' responses to witnessed events. Other areas for research include evaluating patient preferences, assessing the effect of family presence on resuscitation outcomes, and determining the longer-term effects of this practice on family members and providers.

\section{THE CONTINUED DEBATE}

While it is clear that more rigorous work is needed on family presence, history suggests that more research 
may not be all we need to bring resolution to this debate, because intense emotional responses may defy research results. In the debate over fathers' presence during childbirth, widespread endorsement was not immediate, even in the face of evidence supporting such policies. Some physicians continued to voice strong concerns even after becoming aware of the beneficial effects of fathers' presence. For example, one obstetrician noted that, while the husband's presence in the labor room provided helpful emotional support to the patient, "... having the husband in the Delivery Room is something else again!"11

As we reflect upon the past debate over fathers' presence at childbirth, it is helpful to remember that those doctors who opposed fathers' presence during childbirth had laudable motives. They worried about compromising the care given to the patient, who was their primary responsibility, and about untoward effects on the new father. However, with experience and education, obstetricians realized that their goal of providing the best possible care for their patients was not at odds with the desire of fathers to be present. This realization was the basis for a fundamental shift in physician attitudes toward patients and their families. Obstetricians began to look at caring for the father as part of their responsibility of caring for the mother.

Today, it is clear that emergency providers who oppose family presence during resuscitation also have laudable motives. They see the patient as their primary responsibility and worry that the presence of relatives will undermine their care of that patient. Moreover, they are concerned about potential negative effects on witnessing family members. Here again, evidence suggests that experience and education will change physician attitudes regarding the benefits of family presence policies. Physicians who experience family presence firsthand often change their minds on this issue. In a letter to The Journal of Trauma, Dr. James Barone explained how allowing the family of a 9-yearold girl in to see her while resuscitation activities were in progress changed his opinion of family presence:

"I had previously opposed any intrusion into the sacred domain of the trauma resuscitation room by patients' families. I now realize that under the proper circumstances ... the presence of the family may actually be a good thing for everyone, including the caregivers." ${ }^{22}$

Another physician made similar comments after a family presence program was implemented at his hospital: "I was very much against [family presence] when we started. Now that that I have seen the benefits to families and staff, I endorse it strongly."17

As we move forward with our current debate over family presence, we hope that we can learn from the past and simply keep our minds open. We encourage health care professionals to approach this topic objectively; remembering that we have been wrong before, and undoubtedly will be again.-Margaret B. Kopelman, BBA, Medical School, University of Michigan, Ann Arbor, MI; Peter A. Ubel, MD, Division of General Internal Medicine, University of Michigan, Ann Arbor, MI, VA Ann Arbor Healthcare System, Ann Arbor, MI, Program for Improving Health Care Decisions, Ann Arbor, MI, and Robert Wood Johnson Clinical Scholars Program, University of Michigan, Ann Arbor, MI; and Kirsten G. Engel, MD (kirsten.engel@yale.edu), Department of Emergency Medicine, University of Michigan, Ann Arbor, MI, and Robert Wood Johnson Clinical Scholars Program, University of Michigan, Ann Arbor, MI

doi:10.1197/j.aem.2005.05.027

The authors thank Judith Leavitt and Martin Pernick for their historical expertise and valuable suggestions regarding background research for this paper. The authors are very grateful for the insightful comments received from Robert Silbergleit on a previous draft of the manuscript.

\section{References}

1. Helmer SD, Smith RS, Dort JM, Shapiro WM, Katan BS. Family presence during trauma resuscitation: a survey of AAST and ENA members. J Trauma Inj Infect Crit Care. 2000; 48:1015-22; discussion 1023-4.

2. Mitchell MH, Lynch MB. Should relatives be allowed in the resuscitation room? J Accid Emerg Med. 1997; 14:366-9; discussion 370.

3. McClenathan BM, Torrington KG, Uyehara CF. Family member presence during cardiopulmonary resuscitation: a survey of US and international critical care professionals. Chest. 2002; 122:2204-11.

4. Pafford MB. Should family members be present during CPR? J Ark Med Soc. 2002; 98:304-6.

5. Aries P. Hour of Our Death. New York: Vintage Books (Division of Random House), 1982.

6. Leavitt JW. Brought to Bed: Childbearing in America 1750-1950. New York: Oxford University Press, 1986.

7. Morton JH. Fathers in the delivery room-an opposition standpoint. Hosp Top. 1966; 44:103-4.

8. Miller JS. "Return the joy of home delivery" with fathers in the delivery room. Hosp Top. 1966; 44:105-9.

9. Bradley RA. Fathers' presence in delivery rooms. Psychosomatics. 1962:474-9.

10. Hayden GE, Moore DC, Bridenbaugh LD. Maternity care should be family centered. Mod Hosp. 1964; 102(2):104-5.

11. Sehgal NN. The potential for problems when husbands are in the delivery room. Resident Staff Physician. 1973; 33-5.

12. Aldridge $\mathrm{CW}$ Jr. Initial experiences with fathers in the delivery room. Mich Med. 1970; 69:489-91.

13. Goetsch C. Fathers in the delivery room-"helpful and supportive." Hosp Top. 1966; 44(1):104-5.

14. Meyers TA, Eichhorn DJ, Guzzetta CE, et al. Family presence during invasive procedures and resuscitation. Am J Nurs. 2000; 100:32-42.

15. Doyle CJ, Post H, Burney RE, Maino J, Keefe M, Rhee KJ. Family participation during resuscitation: an option. Ann Emerg Med. 1987; 16:673-5.

16. Hanson C, Strawser D. Family presence during cardiopulmonary resuscitation: Foote Hospital emergency department's nine-year perspective. J Emerg Nurs. 1992; 18:104-6.

17. Belanger MA, Reed S. A rural community hospital's experience with family-witnessed resuscitation. J Emerg Nurs. 1997; 23:238-9.

18. Robinson SM, Mackenzie-Ross S, Campbell Hewson GL, Egleston CV, Prevost AT. Psychological effect of witnessed 
resuscitation on bereaved relatives. Lancet. 1998; 352: 614-7.

19. Boyd R, White S. Does witnessed cardiopulmonary resuscitation alter perceived stress in accident and emergency staff? Eur J Emerg Med. 2000; 7:51-3.

20. Eichhorn DJ, Meyers TA, Guzzetta CE, et al. Family presence during invasive procedures and resuscitation: hearing the voice of the patient. Am J Nurs. 2001; 101: $48-55$.

21. Benjamin M, Holger J, Carr M. Personal preferences regarding family member presence during resuscitation. Acad Emerg Med. 2004; 11:750-3.

22. Barone JE. Family presence during trauma resuscitation [letter]. J Trauma Inj Infect Crit Care. 2001; 50:386. 